\title{
HOUSEHOLD/ZONAL SOCIOECONOMIC CHARACTERISTICS AND TOUR MAKING: CASE OF RICHMOND/TRI-CITIES MODEL REGION IN VIRGINIA
}

\author{
Xueming CHEN \\ Virginia Commonwealth University, United States
}

\begin{abstract}
This paper statistically assesses the impacts of household/zonal socio economic characteristics on tour making within the Richmond/Tri-Cities Model Region, Virginia, United States, based on the dataset made available through the 2009 Virginia National Household Travel Survey (NHTS) Add-On Program. The tour analysis distinguishes nine tour types (three simple tours and six complex tours) stratified by aggregate tour purposes of work (including school and other subsistence activities), maintenance and discretionary. A series of regression model runs have yielded the following conclusions: First, at aggregate level, the number of drivers, median household income, household size, number of workers, and zonal walking modal share are statistically significant and positively impact tour frequency. Tour length and complexity are positively related to household income and number of vehicles, but negatively related to zonal walking modal share. Second, at an individual tour type level, each tour type's frequency/length/complexity is impacted by a different set of household/zonal socioeconomic characteristics. Zonal socioeconomic characteristics have little or no impacts on household tour making. It is recognized that many unknown factors may also have impacted tour activities, which require further in-depth studies in order to better explain complex tours.
\end{abstract}

Key Words: tour, Richmond/Tri-Cities model region, household and zonal socio-economic characteristics, regression model

\section{Introduction}

In 2007, the Transportation Research Board (TRB) published a Special Report 288: Metropolitan Travel Forecasting, Current Practice and Future Directions, which recommends that Metropolitan Planning Organizations (MPOs) and other agencies in the United States using travel demand models begin to transition from the prevailing four-step modeling paradigm to more advanced model forms (for example, improved land use modeling, tour-based models, activity-based models, discrete-choice modeling, supply-side models, TRANSIMS, and others) in order to more effectively respond to new policy and planning requirements (TRB 2007).

In 2009, in response to this TRB Special Report 288, the Virginia Department of Transportation (VDOT) put out a Virginia Transportation Modeling (VTM) research report entitled "Implementing Activity-Based Models in Virginia." Based on its thorough and objective analysis, the VDOT report recommends an incremental approach to advanced model development, including activity-based models (ABMs). VDOT (2009) recognizes that many challenging requirements (e.g., data, forecast, software, staffing) must be met in order to develop an ABM in Virginia. The development of a fully operational statewide ABM will probably take many years and cost several million dollars before its completion.

In line with the long-term goal of ABM development in Virginia, this paper intends to conduct a tour making analysis based on the empirical data provided by the 2009 Virginia National Household Travel Survey (NHTS) Add-On Program. Due to space limitation, this paper only 
concentrates on the Richmond/Tri-Cities Model Region in Virginia ("the study area") and limits its scope of work to statistically examining the relationship between household/zonal socioeconomic characteristics and tour making (tour frequency, length, and complexity). Since this is a demand-side analysis and the basic unit of analysis for NHTS is the household, household socioeconomic characteristics are thus critically important. Meanwhile, it may also be worth testing the impacts of zonal-level socioeconomic characteristics on household tour-making as well, since nobody has ever done this test before. This study intends to set a preliminary stage for more in-depth disaggregated tour- and activity-based analyses in the future.

Following this introduction, the rest of this paper is divided into six sections. First, Section 2 provides a literature review. After that, Section 3 presents a research methodology. Subsequently, Section 4 provides an overview of the Richmond/Tri-Cities Model Region, with an emphasis on its socioeconomic and travel characteristics. Section 5 examines the statistical relationship between tour frequency/distance/complexity and household/zonal socioeconomic characteristics. Based on empirical analysis, Section 6 discusses the research results and remaining limitations. Finally, Section 7 summarizes research findings and it draws conclusions.

\section{Literature Review}

Activity-based travel demand analysis is believed to have two major advantages over the existing four-step models by providing a better understanding of travelers' responses to transportation policies and programs and an explicit analysis of complex travel patterns such as trip-chaining behavior (Lee et al. 2007). According to VHB (2006), ABMs, by definition, use the tour (rather than the trip) as the basic unit of travel and they are therefore also called tourbased models. It is the tour-based analysis that lays the foundation for ABM development.

Over the past four decades, many ABM models have been developed with various degrees of application successes. The earliest ABMs have been developed within the context of European national models in countries such as the Netherlands (Hague Consulting Group 1992), Italy (Cascetta et. al. 1993), Sweden (Algers et. al. 1997) and Denmark (Fosgerau 2002).

In Canada, Miller et. al. (2005) uses the 1996 Transportation Tomorrow Survey (TTS) data in the Greater Toronto Area (GTA) to develop the tour-based model of travel mode choice. A key organizing principle in the model is that if a car is to be used on a tour, it must be used for the entire chain, since the car must be returned home at the end of the tour. No such constraint, however, exists with respect to other modes, such as walk and transit.

In their review of models of Australian capital cities, SKM (2009) found that the Sydney Strategic Travel Model (STM) was the only Australian capital city model which was tour-based (the others being trip-based). Milthorpe and Daly (2010) take travel data from the Sydney Household Travel Survey and analyze it using both trip and tour methodologies. Comparisons are then made on the results from this analysis. Major differences include insights into non-home based travel, the proportion of journeys which involve deviations (intermediate stops) and the resulting additional kilometrage. Also, as most people start and finish the day at home, it is possible to examine the symmetry, or otherwise, for outward (away from home) and return (towards home) tour legs. They also find that the travel purposes have different duration and time of day profiles.

The most important U.S. based ABM applications include Simulation-based Applications; Computational Process Models (CPM); Hazard-Based Duration Models; Econometric-based 
Household/Zonal Socioeconomic Characteristics and Tour Making:

Case of Richmond/Tri-Cities Model Region in Virginia

Applications; Mathematical Programming Approaches; TRansportation ANalysis and SIMulation System (TRANSIMS); Discrete and Discrete-Continuous Choice Models; Structural Equation Models; and others (Bhat 1997, Bowman and Ben-Akiva 1997, Gärling et. al. 1994, Golob and McNally 1995, Kitamura 1996, McNally 2007, Pas 1997, Recker 1995, USDOT 1997).

Sometimes called stop-making behavior, trip-chaining behavior in activity-based modeling describes the importance of multi-purpose trip-making rather than single trip-making. Numerous studies have examined trip-chaining or stop-making models using the frequency of stops on the way home and/or on the way to work as dependent variables (Bhat 1999, Bhat and Singh 2000, Chu 2003, Shiftan 1998, Wallace et al. 2000). In these studies, the stop-making behavior is derived from the activity-based concept and it is used to describe stopping behavior made by a traveler, in particular a commuter, on the way to home or work. With the assumption that a commuter has a regularly followed route, stopping at a location away from home or work during commuting in order to participate in an activity is treated as a deviation from the commute trip. Therefore, in prior research, stop-making models were usually applied with respect to linking non-work activities with work activities, including the morning commute, midday trips, evening commute, and trips before or after the commute (Bhat 1999, Bhat and Singh 2000, Wallace et al. 2000). In addition to work trips, non-workers' trip-chaining as a series of out-of-home activity episodes (or stops) of different types interspersed with periods of in-home stays have also been investigated (Bhat and Misra 2001, Misra et al. 2003).

In spite of its conceptual novelty and model development progresses, the inherent complexity of activity behavior, data availability and collection cost, compatibility with existing full-step model (FSM) results and the risks it causes, existing agencies' modeling capability and ABM's lack of solid theoretical framework have prevented the widespread applications of ABMs in the U.S. and elsewhere. In the U.S., the following planning agencies have taken the lead in developing and applying the activity-/tour-based models: San Francisco County Transportation Authority (SFCTA), Metropolitan Transportation Commission (MTC), Denver Regional Council of Governments (DRCOG), New York Metropolitan Transportation Commission (NYTMC), Mid-Ohio Regional Planning Commission (MORPC), Tahoe Regional Planning Agency (TRPA), Sacramento Area Council of Governments (SACOG), Atlanta Regional Commission (ARC), and New Hampshire Department of Transportation (Statewide), and others. In addition, Portland Metro and Texas Department of Transportation are actively experimenting with and testing the tour-based models.

It is noticed that ABM concepts have recently been applied not only to model development, but also to planning research. For example, Krizek (2003) offers a typology of travel tours to account for different travel purposes and analyzes the relationships between tour type and neighbourhood access using detailed travel data from the Central Puget Sound Region. This paper takes a similar approach for the Richmond/Tri-Cities Model Region by examining the impacts of household/zonal socioeconomic characteristics on local tour making.

\section{Research Methodology}

\section{Data Sources}

The primary data source of this study is the 2009 Virginia NHTS Add-On Program. The add-on sample size for the entire Virginia is 15,231 households and 117,544 trips, which includes 2,273 households and 17,075 trips for the Richmond/Tri-Cities Model Region. 
The data set for the study area includes household, person, vehicle, and trip/location tables.

This study primarily uses trip/location table, which already includes each traveler's most important household information. The paper uses household tour as the unit of analysis, which is aggregated from individual trip information.

The secondary data source is the 2008 socioeconomic data for all traffic analysis zones (TAZ) within the study area. TAZ-level population, household, automobile and employment densities may impact individual trips and household tours, which remain to be tested.

\section{Tour Definitions}

Activities in a household used for satisfying human needs are classified into three categories: subsistence (work or work-related business), maintenance (grocery shopping, personal and household business, and pick-up/drop-off passengers), and leisure (social and recreational purposes). Subsistence and maintenance are household needs, and leisure is formed by the need of the individual (Reichman 1976).

Following the tour type classification and terms used by Krizek (2003), this paper also assumes nine home-anchored tour types for the study area (Note: H=Home; W=Work; $M=$ Maintenance; $\mathrm{D}=$ Discretionary):

- $\quad$ Type 1: Simple Work $(\mathrm{H}-\mathrm{W}-\mathrm{H})$;

- $\quad$ Type 2: Simple Maintenance (H-M-H);

- $\quad$ Type 3: Simple Discretionary (H-D-H);

- $\quad$ Type 4: Complex Work Only (H-W-W-...-H);

- $\quad$ Type 5: Complex Maintenance Only or Complex Discretionary Only (H-M-M-...-H or H-D $-\mathrm{D}-. . .-\mathrm{H})$;

- $\quad$ Type 6: Complex Work + Maintenance Only $(\mathrm{H}-\mathrm{W}-\mathrm{M}-\ldots-\mathrm{H})$. Note: Tripmaking could take place in any order:

- $\quad$ Type 7: Complex Work + Discretionary Only (H-W-D-...-H). Note: Tripmaking could take place in any order;

- $\quad$ Type 8: Complex Maintenance + Discretionary Only (H-M-D-...-H). Note: Tripmaking could take place in any order;

- Type 9: Complex Work + Maintenance + Discretionary (H-W-M-D-...-H). Note: Tripmaking could take place in any order.

In the above tour type classification, the term "Work" is a subsistence activity including incomeproducing or paid time like work or school (Lee et al. 2007).

\section{Research Hypotheses}

This study makes the following hypotheses regarding the impacts of household/zonal socioeconomic characteristics on aggregate household-level tour-making (combining all tour purposes):

First, tour frequency is negatively related to tour length. Shorter tours are more frequent than longer-tours; 
Second, tour length is positively related to tour complexity. In other words, longer tours are more likely to have intermediate stops or trips for each tour;

Third, the household socioeconomic characteristics have much more significant impacts on aggregate household-level tour-making than zonal socioeconomic characteristics.

In the meantime, it should be pointed out that at the disaggregated levels, the impacts of socioeconomic characteristics on household-level tour-making vary by tour purposes.

\section{Analytical Approaches}

For each tour type, including aggregate type (combining all tour purposes), this study uses Poisson regression (for count data) to estimate the impacts of household/zonal socioeconomic characteristics on tour frequency (measured by number of tours per household), and applies Ordinary Least Squares (OLS, for continuous data) regression models in the estimation of the impacts of household/zonal socioeconomic characteristics on tour length (measured by miles per tour) and tour complexity (measured by trips per tour). Table 1 shows the list of variables used in these regression models. Each regression model, though with a different dependent variable, has the same set of independent variables.

\section{List of Variables}

\begin{tabular}{|c|c|c|}
\hline Regression Model & $\begin{array}{c}\text { Dependent } \\
\text { Variables (DVs) }\end{array}$ & Independent variables (IVs) \\
\hline Poisson Regression & $\begin{array}{l}\text { AGGHHFREQ } \\
\text { (Tour frequency) }\end{array}$ & \multirow[b]{3}{*}{$\begin{array}{l}\text { Household Socioeconomic Characteristics } \\
\text { DRVRCNT (Number of drivers in a household); } \\
\text { HHFAMINC (Median household income); } \\
\text { HHSIZE (Household size); } \\
\text { HHVEHCNT (Number of vehicles in a house- } \\
\text { hold); } \\
\text { NUMADLT (Number of adults in a household); } \\
\text { WRKCOUNT (Number of workers in a house- } \\
\text { hold); } \\
\text { CARRATIO (Average automobile modal share } \\
\text { of a tour); } \\
\text { WALKRATIO (Average walking modal share of } \\
\text { a tour); } \\
\text { AVGAUTO (Autos per household); } \\
\text { Zonal Socioeconomic Characteristics } \\
\text { POPDEN (Population/square mile); } \\
\text { HHDEN (Households/square mile); } \\
\text { AUTODEN (Autos/square mile); } \\
\text { TEMPDEN (Total employment/square mile). }\end{array}$} \\
\hline OLS Regression & $\begin{array}{l}\text { AVGHHMIL } \\
\text { (Tour length) }\end{array}$ & \\
\hline OLS Regression & $\begin{array}{l}\text { AVGHHTRIP1TOU } \\
\text { R } \\
\text { (Tour complexity) }\end{array}$ & \\
\hline
\end{tabular}

For Poisson Regression, AIC (Akaike Information Criterion) and Wald ChiSq are used to test model and parameter significance, respectively, whereas for OLS Regression, R-Square and $t$ value are used to test model and parameter significance, respectively. 


\section{Richmond/Tri-Cities Model Region: Facts at a Glance}

\section{Geographic Setting}

As the capital city of the Commonwealth of Virginia, Richmond City is the central city of the Richmond/Tri-Cities Model Region, or the greater Richmond area. At present, the Richmond/Tri -Cities Model Region (1,792 square miles; 1.2 million existing residents; 980 internal traffic analysis zones, or TAZs) contains the two urban regions: Richmond City and the Tri-Cities (Petersburg, Hopewell and Colonial Heights), plus other surrounding counties. It is bounded by the Fredericksburg Model Region to the north and extends into New Kent and Charles City counties, but does not border the Hampton Roads Model Region. The James River bisects the study area. Major interstates crossing the region are Interstates 64 and 95 (intersecting in Richmond) and Interstate 85 (intersecting I-95 near Petersburg). Figure 1 shows the map of Richmond/Tri-Cities Model Region.

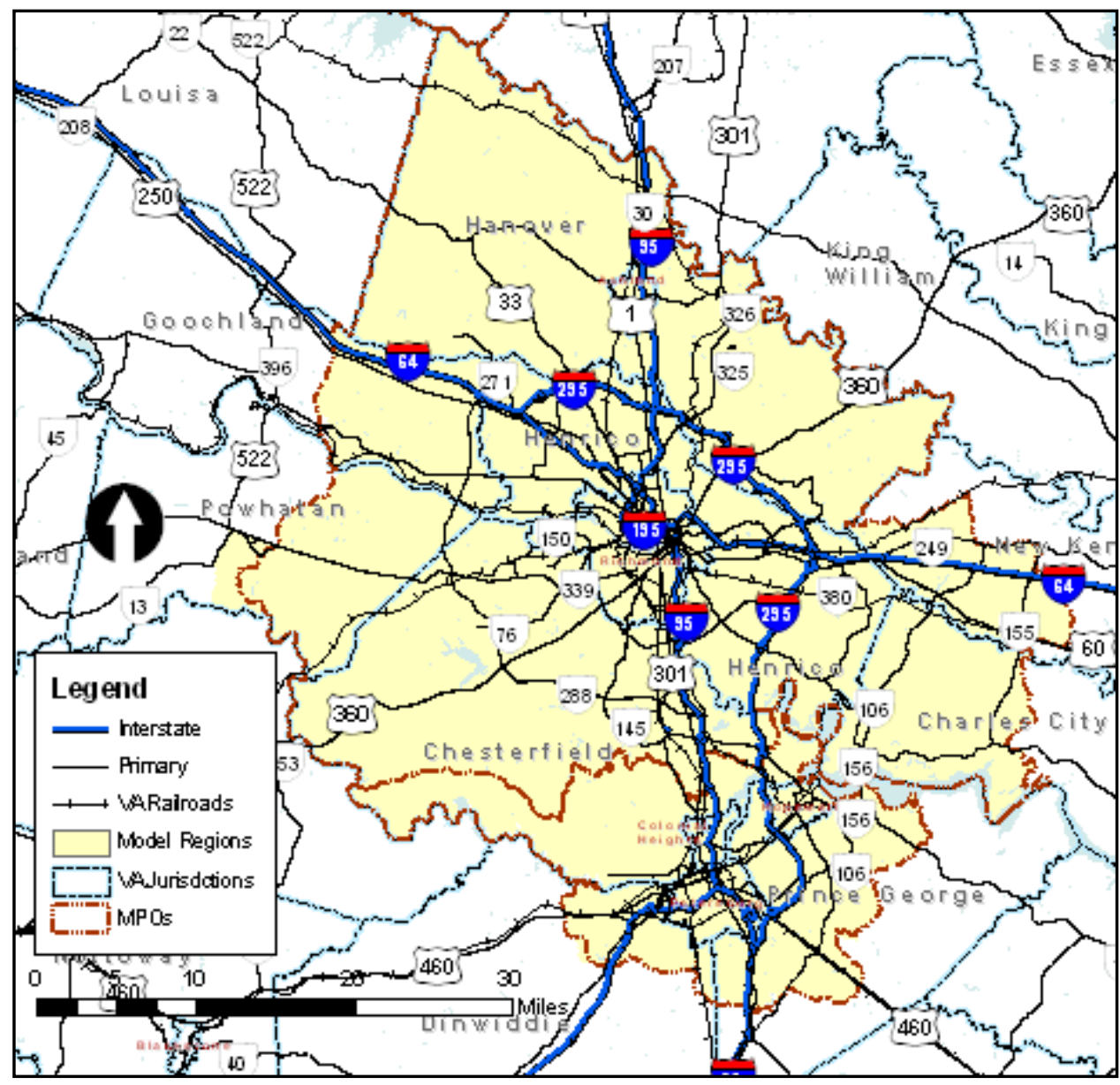

Fig. 1 - Map of Richmond/Tri-Cities Model Region 
Household/Zonal Socioeconomic Characteristics and Tour Making: Case of Richmond/Tri-Cities Model Region in Virginia

Impacts of Socioeconomic Characteristics on Tours

\section{Tour Descriptive Statistics}

In this paper, a tour is defined as a set of trip segments that begin and end at an individual's home, irrespective of dwell time at each stop. The correspondence between the tour codes assigned (TOURCODE) and summary trip purposes (WHYTRP1S) is shown in Table 2.

Correspondence between TOURCODE and WHYTRP1S

Table 2

\begin{tabular}{|l|l|}
\hline \multicolumn{1}{|c|}{ TOURCODE } & \multicolumn{1}{|c|}{ WHYTRP1S } \\
\hline $\mathrm{H}$ (Home) & 01 (Home) \\
\hline W (Work) & 10 (Work) \\
\hline M (Maintenance) & 20 (School/Daycare/Religious activity) \\
& 30 (Medical/Dental services) \\
& 40 (Shopping/Errands) \\
& 60 (Family personal business/Obligations) \\
\hline D (Discretionary) & 50 (Social/Recreational) \\
& 70 (Transport someone) \\
& 80 (Meals) \\
& 97 (Other reason) \\
\hline NA (Not Applicable) & -7 (Refused) \\
& -8 (Do not know) \\
\hline
\end{tabular}

This study examines three simple tours ( 2 trips per tour) and six complex tours ( $>2$ trips per tour). As shown in Table 3, the total number of home-anchored sample tours in the study area amounted to 5,368 tours with the following breakdown:

- $\quad$ Almost $60 \%$ of these tours were simple tours with the following tour purposes: Simple Maintenance (24.91\%), Simple Discretionary (24.59\%), and Simple Work (9.58\%). Note: Simple Work used here is a generic term, including work, school, and other subsistence activities;

- $\quad$ For the remaining complex tour types, the most important tour purposes were: Complex Maintenance + Discretionary Only (15.03\%), Complex Maintenance Only or Complex Discretionary only (14.08\%). All other tour purposes were relatively less important.

Complex tours had a longer mean travel distance than simple tours. Within simple tours, Simple Work tours had a much longer mean travel distance than Simple Maintenance tours and Discretionary tours. Complex Work + Maintenance + Discretionary had the longest mean travel length due to its complicated trip chains. Generally speaking, work tours more likely use freeway system due to its longer commuting distance, whereas short-distanced maintenance tours may use local arterial streets to access neighborhood/community stores. As a result, mean speed for work-related tours is faster than that for maintenance-/discretionary-related tours. By definition, simple tours (work, maintenance, discretionary) only have two trips per tour (origin-destination and destination-origin). The most complex Type 9 tour has most trips per tour (6.26). All other complex tours have mean trips per tour ranging from 3.57 to 4.55 . 
Tour Classification and Descriptive Statistics for the Study Area

\begin{tabular}{|c|c|c|c|c|c|c|c|c|}
\hline $\begin{array}{l}\text { Type } \\
\#\end{array}$ & Tour type & Coding & $\begin{array}{l}\text { \# of } \\
\text { tours }\end{array}$ & $\begin{array}{l}\text { \% of } \\
\text { tours }\end{array}$ & 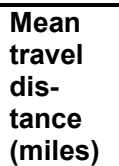 & $\begin{array}{l}\text { Mean } \\
\text { travel } \\
\text { time } \\
\text { (minu- } \\
\text { tes) }\end{array}$ & $\begin{array}{l}\text { Mean } \\
\text { Speed } \\
\text { (miles / } \\
\text { hour) }\end{array}$ & $\begin{array}{l}\text { Mean } \\
\text { trips } \\
\text { per } \\
\text { tour }\end{array}$ \\
\hline 1 & Simple Work & $\mathrm{H}-\mathrm{W}-\mathrm{H}$ & 514 & 9.58 & 25.98 & 45.84 & 34.01 & 2.00 \\
\hline 2 & $\begin{array}{l}\text { Simple Mainte- } \\
\text { nance }\end{array}$ & $\mathrm{H}-\mathrm{M}-\mathrm{H}$ & 1,337 & 24.91 & 11.92 & 31.98 & 22.37 & 2.00 \\
\hline 3 & $\begin{array}{l}\text { Simple Discre- } \\
\text { tionary }\end{array}$ & $\mathrm{H}-\mathrm{D}-\mathrm{H}$ & 1,320 & 24.59 & 14.22 & 33.63 & 25.37 & 2.00 \\
\hline 4 & $\begin{array}{l}\text { Complex Work } \\
\text { Only }\end{array}$ & $\mathrm{H}-\mathrm{W}-\mathrm{W}-\ldots-\mathrm{H}$ & 47 & 0.88 & 74.95 & 123.40 & 36.44 & 4.55 \\
\hline 5 & $\begin{array}{l}\text { Complex } \\
\text { Maintenance } \\
\text { Only or Com- } \\
\text { plex Discretion- } \\
\text { ary Only }\end{array}$ & $\begin{array}{l}\text { H-M-M-...-H } \\
\text { or } \\
\text { H-D-D-...-H }\end{array}$ & 756 & 14.08 & 25.48 & 57.74 & 26.48 & 3.57 \\
\hline 6 & $\begin{array}{l}\text { Complex Work } \\
+ \text { Maintenance } \\
\text { Only }\end{array}$ & $\mathrm{H}-\mathrm{W}-\mathrm{M}-\ldots-\mathrm{H}^{*}$ & 227 & 4.23 & 37.11 & 73.72 & 30.20 & 3.97 \\
\hline 7 & $\begin{array}{l}\text { Complex Work } \\
\text { + Discretionary } \\
\text { Only }\end{array}$ & $\mathrm{H}-\mathrm{W}-\mathrm{D}-\ldots-\mathrm{H}^{*}$ & 200 & 3.73 & 41.21 & 77.37 & 31.96 & 4.00 \\
\hline 8 & $\begin{array}{l}\text { Complex } \\
\text { Maintenance + } \\
\text { Discretionary } \\
\text { Only } \\
\end{array}$ & $\mathrm{H}-\mathrm{M}-\mathrm{D}-\ldots-\mathrm{H}^{*}$ & 807 & 15.03 & 57.71 & 91.62 & 37.79 & 4.43 \\
\hline 9 & $\begin{array}{l}\text { Complex Work } \\
\text { + Maintenance } \\
\text { + Discretionary }\end{array}$ & $\begin{array}{l}\mathrm{H}-\mathrm{W}-\mathrm{M}-\mathrm{D}-\ldots- \\
\mathrm{H}^{*}\end{array}$ & 160 & 2.98 & 90.93 & 129.66 & 42.08 & 6.26 \\
\hline Total & & & 5,368 & 100 & & & & \\
\hline
\end{tabular}

Note: *Tripmaking could take place in any order

\section{Tour Regression Analysis Results}

This section reports two sets of regression analysis results: aggregate level (combining all tour purposes) and tour type level. The aggregate level results combine the results of all nine tour types together, whereas tour type level results show each individual tour results one by one. Appendices 1 through 3 show the modeling results for tour frequency, tour length, and tour complexity, respectively. All significant results are bolded.

\section{Aggregate Level Analysis Results}

Appendix 1 indicates that variables representing household characteristics [number of drivers (DRVRCNT), median household income (HHFAMINC), household size (HHSIZE), and number of workers (WRKCOUNT)], walking modal share (WALKRATIO), and TAZ automobile density (AUTODEN) have p-values less than 0.05 , therefore they are statistically significant at 0.05 levels. All of these variables positively impact tour frequency. This finding is reasonable because a household with more people, higher income level and walking modal share will take 
more tours. The TAZs with higher automobile density are typically located in the suburban areas with more tours.

With respect to aggregate level tour length, Appendix 2 suggests that tour length is positively related to HHFAMINC and HHVEHCNT, but negatively related to WALKRATIO, meaning higher walking modal shares are associated with shorter tour length.

High-income households tend to live in suburban areas, which will have longer commuting distance. As illustrated in Figure 2, in the Richmond/Tri-Cities Model Region, the TAZs with the longer trip times (greater than 1.3 Standard Deviations from mean travel time) are located in the outlying suburban areas, especially in the southeast corner areas, such as Prince George County, and Charles City County. Most job opportunities are concentrated in Richmond City, which is located in the central part of the study area. The closer the commuters live near Richmond City, the shorter the commuting distance, and vice versa. In the United States, due to the suburbanization movement, high-income households tend to live in suburban areas, whereas low-income households tend to live in central city areas.

As stated earlier, tour complexity is measured by trips per tour. The more trips a tour includes, the more complicated it is. High-income and more-vehicle households tend to make more stops in a tour. Households with higher automobile or walking modal shares tend to make more tours as well, but each tour is less complicated with fewer trips. HHDEN reflects land use density.

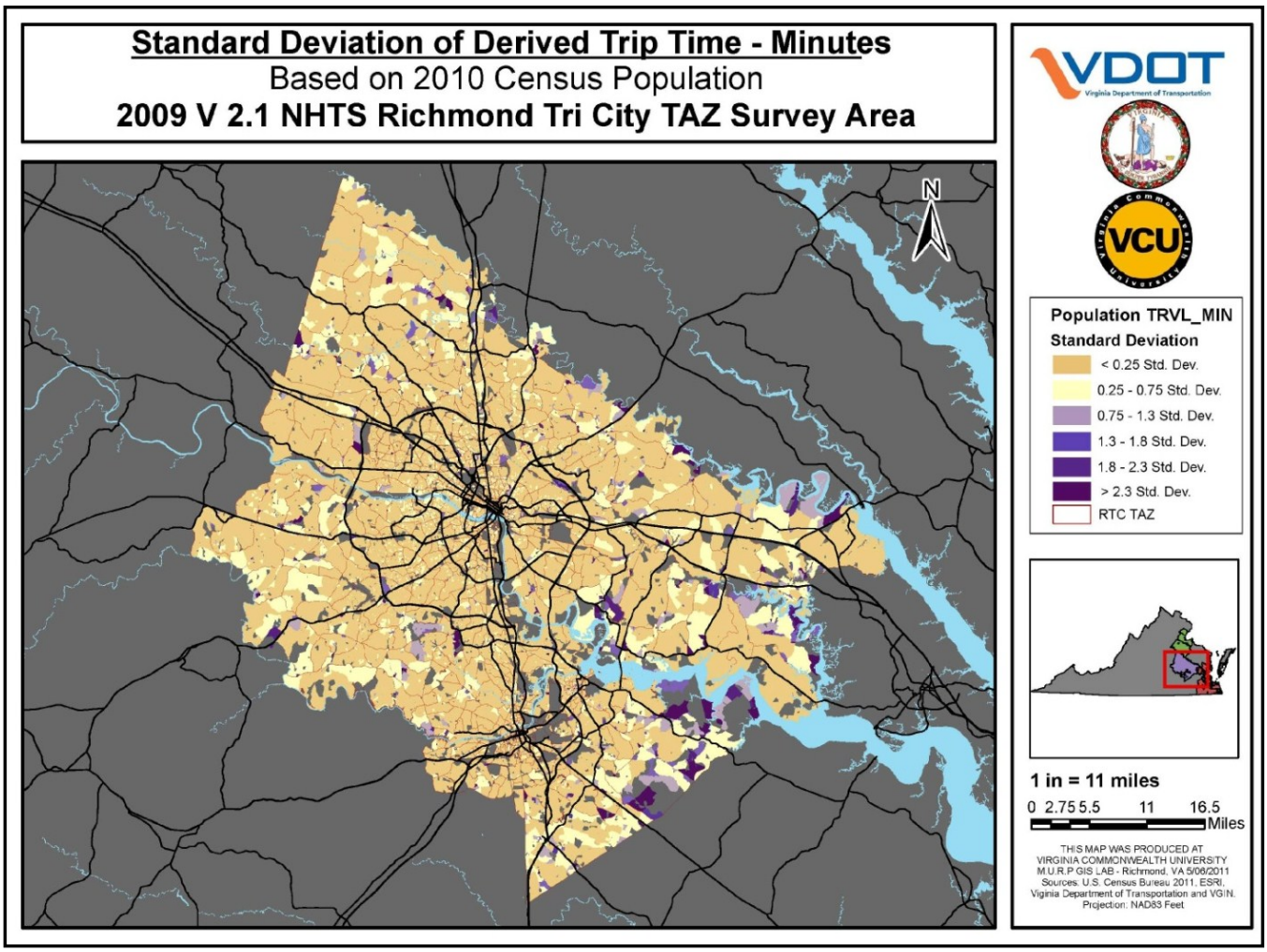

Fig. 2 - Standard Deviation of Derived Trip Time in the Study Area 
Higher land use density typically reduces the number of tours, but each tour has more chained trips. See Appendix 3 for details.

Zonal socioeconomic characteristics have virtually no impacts at all on aggregate level household tour-making, regardless of whether it is measured by tour frequency, tour length, or tour complexity.

Tour Type Level Analysis Results

Having analyzed tours at an aggregate level, it is necessary to conduct a more detailed tour type level analysis, through which the relationship between each tour type's tour frequency/ length/complexity and its associated household/zonal socioeconomic characteristics can be more quantitatively estimated. See Appendices 1-3 for details. For all tour types, zonal socioeconomic characteristics also have low or no impacts on household tour-making, regardless of whether it is measured by tour frequency, tour length, or tour complexity.

\section{Tour Type 1: Simple Work}

For Type 1 tours, no independent variable is statistically significant at 0.05 level for tour frequency. However, number of workers has a much larger impact than other variables. Therefore, there is a direct and positive linkage between number of workers and number of Simple Work tours.

With respect to its tour length, the statistically significant variables at 0.05 level are HHFAMINC (positively related) and WALKRATIO (negatively related). Those households with a higher HHFAMINC are typically located in suburban areas with longer commuting distance or tour length. A higher WALKRATIO figure implies either a lower vehicle ownership rate or a lower automobile modal share, which is typically associated with shorter tour length.

Since a Simple Work tour only has 2 constant trips for all households, no regression is run for dependent variable AVGHHTRIP1TOUR (measuring tour complexity).

\section{Tour Type 2: Simple Maintenance}

For Type 2 tours, the only statistically significant variable at 0.05 level impacting tour frequency is household size (HHSIZE). Household size positively impacts the number of Simple Maintenance tours made. A larger household needs more shopping and other maintenance trips to meet everyone's needs.

Type 2 tour length is negatively impacted by WALKRATIO for the similar reasons as those of Type 1 tour. Since a Simple Maintenance tour only has 2 constant trips for all households, no regression is run for dependent variable AVGHHTRIP1TOUR (measuring tour complexity).

\section{Tour Type 3: Simple Discretionary}

Type 3 tour frequency is significantly impacted by HHFAMINC (positively related), HHSIZE (positively related), and WRKCOUNT (negatively related). It is reasonable for a higher-income and larger-sized household to make more discretionary trips (e.g. leisure and entertainment). In contrast, a household with more workers tends to make more commuting trips and thus less discretionary trips. 
Household/Zonal Socioeconomic Characteristics and Tour Making:

Case of Richmond/Tri-Cities Model Region in Virginia

Type 3 tour length is negatively impacted by WALKRATIO, which is similar to both Type 1 and Type 2 tours. Since a Simple Discretionary tour only has 2 constant trips for all households, no regression is run for dependent variable AVGHHTRIP1TOUR (measuring tour complexity).

\section{Tour Type 4: Complex Work Only}

It is worth noting that no variables significantly impact Type 4 tour frequency and tour length. Only household density (HHDEN) negatively impacts tour complexity. This suggests that Complex Work Only tours are perhaps impacted by other unknown variables yet to be included in future regression model runs with expanded IVs.

\section{Tour Type 5: Complex Maintenance Only or Complex Discretionary Only}

Similarly, no variables significantly impact Type 5 tour frequency for unknown reasons. But number of adults and total employment density significantly affect its tour length. Household size negatively impacts tour complexity.

\section{Tour Type 6: Complex Work + Maintenance Only}

For Tour Type 6, no variables significantly impact its tour frequency for unknown reasons. However, household size positively impacts its tour length, and number of vehicles positively impacts its tour complexity.

\section{Tour Type 7: Complex Work + Discretionary Only}

For Tour Type 7, only walking modal share significantly impacts its tour complexity in a positive way.

\section{Tour Type 8: Complex Maintenance + Discretionary Only}

For Tour Type 8, household size positively impacts its tour frequency. The number of vehicles positively affects its tour complexity.

\section{Tour Type 9: Complex Work + Maintenance + Discretionary}

For the most complicated Tour Type 9, its tour frequency is significantly impacted by number of workers in a negative way.

\section{Discussion}

This study conducts a preliminary statistical analysis to examine the relationship between household/zonal socioeconomic characteristics (Note: TAZ-level household automobile and walking modal shares are included as independent variables) and tour making.

It is appropriate to use Poisson regression for modeling tour frequency and use OLS regression for modeling tour length and tour complexity. Independent variables adequately describe both household and zonal socioeconomic characteristics. This treatment is based on the assumption that a household's tour making should be directly impacted by household socioeconomic characteristics, but may also be impacted by its surrounding neighborhood's land use patterns. Higher land use densities tend to lower a household's trip rates (Leinbach 2004). Therefore, it is worthwhile to test the validity of this assumption. 
The completed regression model runs have yielded pretty reasonable results for all simple tours (work, maintenance, and discretionary). However, their validity in explaining complex tours seems relatively limited. It is very likely that many unknown yet important variables are yet to be included in regression equations.

\section{Conclusions}

This paper documents the research results from the 2009 Virginia NHTS Add-On Program for the Richmond/Tri-Cities Model Region. It statistically assesses the impacts of household/zonal socioeconomic characteristics on tour making within the study area. Overall, household socioeconomic characteristics have direct and large impacts on household tour-making, through the direction and degree of these impacts that vary by tour types. However, zonal socioeconomic characteristics have very low or no impacts on household tour-making.

Through this empirical study, it has also been found that:

- $\quad$ Almost $60 \%$ of the sampled tours in the study area were simple tours, especially maintenance and discretionary tours. Other important complex tour types include Complex Maintenance + Discretionary Only, Complex Maintenance Only or Complex Discretionary Only tours;

- For simple tours, work purpose had a much longer mean travel distance than maintenance and discretionary purposes. Complex tours had a much longer mean travel distance than simple tours. The Complex Work + Maintenance + Discretionary had the longest travel distance due to its complicated trip chains;

- $\quad$ At aggregate level, number of drivers, median household income, household size, and number of workers and walking modal share are statistically significant and positively impact tour frequency. Tour length is positively related to household income and number of vehicles;

- At tour type level, for Tour Type 1, no independent variable is statistically significant for its frequency, even though number of workers seems to have a larger impact. With respect to Type 1 tour length, statistically significant variables are HHFAMINC (positively related) and WALKRATIO (negatively related);

- $\quad$ For Tour Type 2, the only statistically significant variable impacting tour frequency is household size (HHSIZE). Household size positively impacts the number of Simple Maintenance tours made. Its tour length is significantly impacted by WALKRATIO in a negative way;

- $\quad$ Tour Type 3 frequency is significantly impacted by HHFAMINC (positively related), HHSIZE (positively related), and WRKCOUNT (negatively related). A household with more workers tends to make more commuting tours and less discretionary (recreational or entertainment) tours. Type 3 tour length is negatively impacted by walking modal share.

In spite of the above useful findings, it should also be pointed out that this study still has several limitations due to data scarcity and other reasons. For example, this statistical analysis has not taken a look at survey respondents' activity schedules, activity coordination among 


\section{Household/Zonal Socioeconomic Characteristics and Tour Making:}

Case of Richmond/Tri-Cities Model Region in Virginia

household members, time and space constraints, in-home activities, and others. Using a statistical tool also has its inherent weakness: correlation does not mean causality. Those IVs may not definitely have causal relationships with DVs. Therefore, there is still room for further modelling improvement to better simulating travelers' activities and tours.
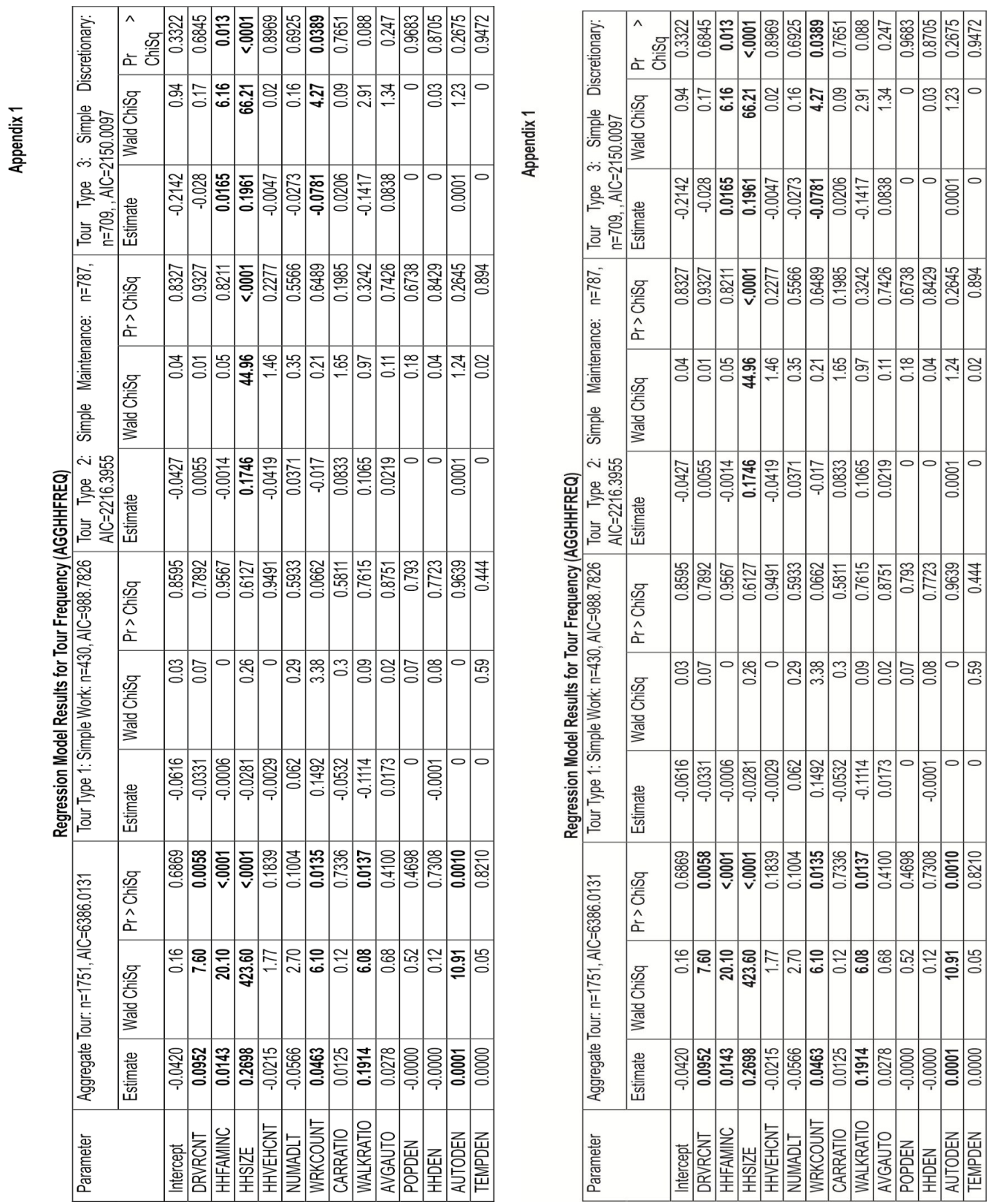

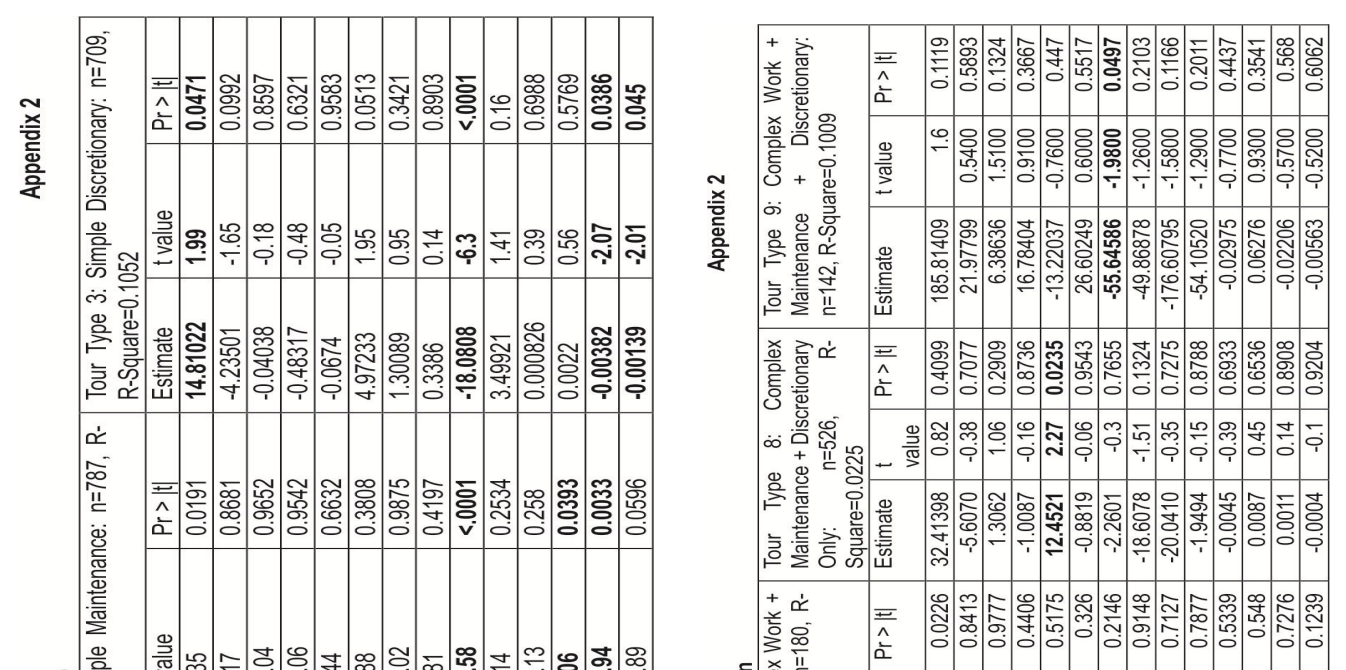

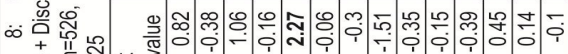

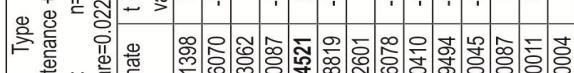

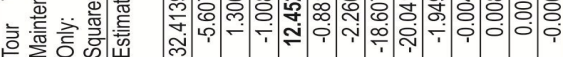

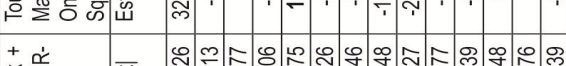

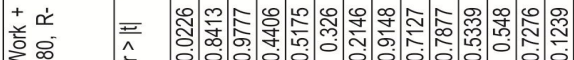

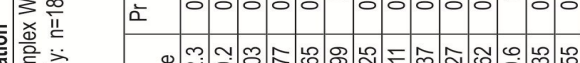
壳蒿言 它芯旁兑

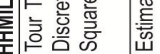

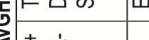

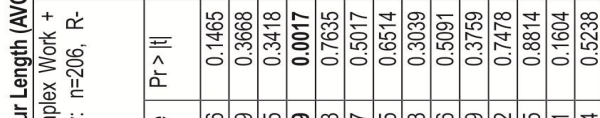
辛突

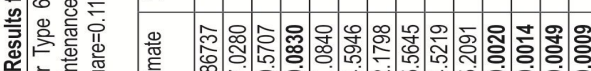
产言喜喜

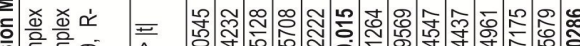
产言言它

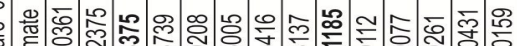

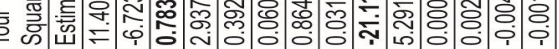

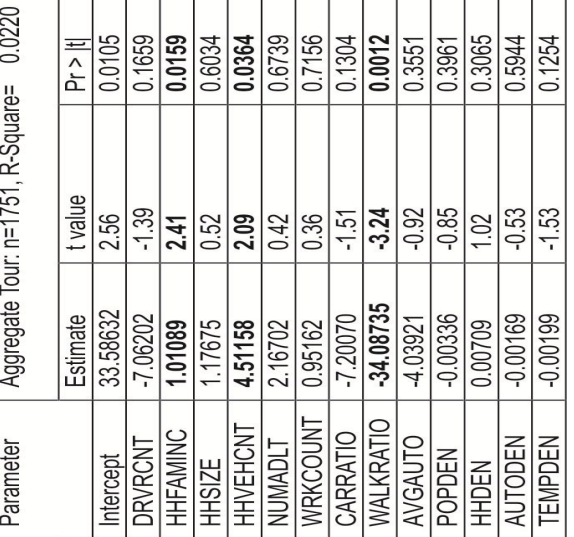

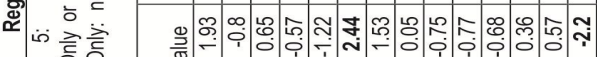

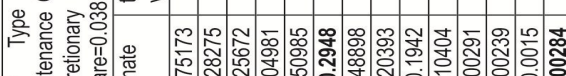

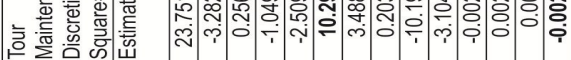

\begin{tabular}{|c|c|c|c|c|c|c|c|c|}
\hline 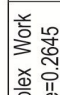 & $\begin{array}{l}\overline{\bar{A}} \\
\hat{\grave{\Lambda}}\end{array}$ & 式 & c) & \begin{tabular}{l|l}
$\bar{\alpha}$ \\
$\vdots$ \\
$\vdots$ \\
0 \\
0
\end{tabular} & 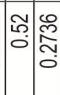 & & & 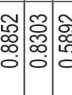 \\
\hline 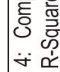 & $\frac{\mathrm{d}}{\frac{9}{3}}$ & 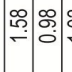 & $\because$ & $\hat{o}: \infty$ & 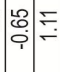 & $\frac{\pi}{c}$ & 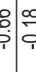 & רُ \\
\hline 흥 & 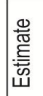 & 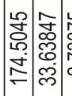 & 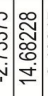 & 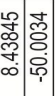 & 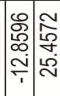 & & & 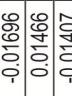 \\
\hline & & 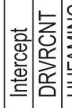 & Ex & 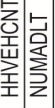 & 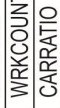 & & & 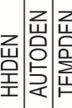 \\
\hline
\end{tabular}


Household/Zonal Socioeconomic Characteristics and Tour Making: Case of Richmond/Tri-Cities Model Region in Virginia

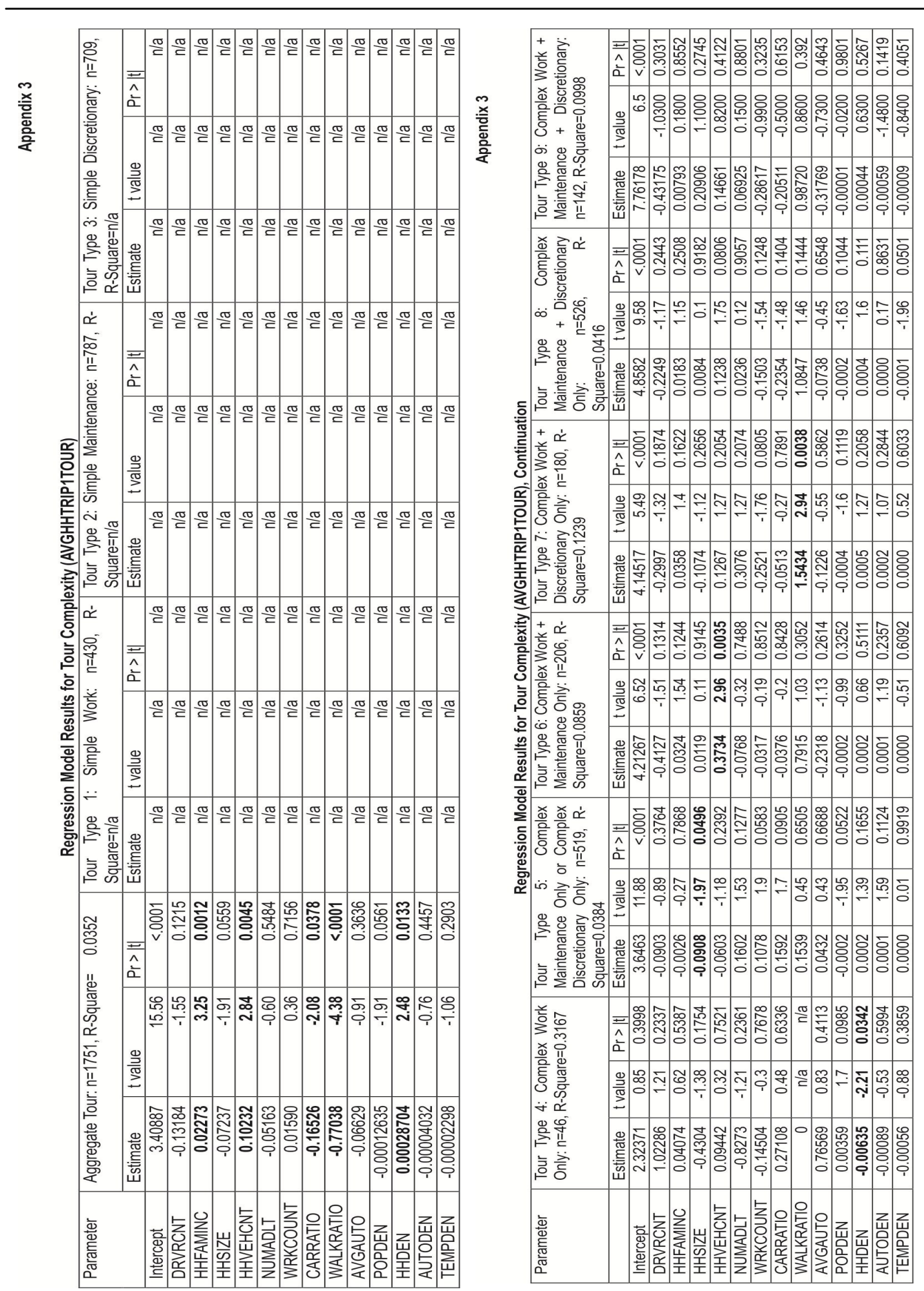




\section{References}

ALGERS S., DALY A. J., WIDLERT S. (1997), Modelling travel behaviour to support policy making in Stockholm, in: Stopher P., Lee-Gosselin M. (eds.), Understanding Travel Behaviour in an Era of Change, Pergamon, Oxford.

BHAT C. (1997), Work Travel Mode Choice and Number of Non-Work Commute Stops, Transportation Research Part B: Methodological 31 (1), 41-54.

BHAT C. (1999), An analysis of evening commute stop-making behavior using repeated choice observations from a multi-day survey, Transportation Research B: Methodological 33 (6), 495-510.

BHAT C. R., MISRA R. (2001), Comprehensive activity travel pattern modeling system for nonworkers with empirical focus on organization of activity episodes, Transportation Research Record 1777, 16-24.

BHAT C. R., SINGH S. K. (2000), A comprehensive daily activity-travel generation model system for workers, Transportation Research Part A: Policy and Practice 34 (1), 1-22.

BOWMAN J., BEN-AKIVA M. (1997), Activity-based Travel Forecasting, Activity-based travel forecasting conference, Department of Transportation, Report DOT-97-17, Washington, DC, U.S.

CASCETTA E., NUZZOLO A., VELARDI V. (1993), A System of Mathematical Models for the Evaluation of Integrated Traffic Planning and Control Policies, Unpublished Research Report, Laboratorio Richerche Gestione e Controllo Traffico, Salerno, Italy.

CHU Y. (2003), Empirical analysis of commute stop-making behavior, Transportation Research Record 1831, 106-113.

FOSGERAU M. (2002), PETRA - An Activity-based Approach to Travel Demand Analysis, In: Lundqvist L., Mattsson L.-G. (Eds.), National Transport Models: Recent Developments and Prospects, Springer, Stockholm.

GÄRLING T., KWAN M. P., GOLLEDGE R. G. (1994), Computational process modeling of household activity scheduling, Transportation Research Part B: Methodological 28 (5), 355364.

GOLOB T. F., MCNALLY M. G. (1995), A model of household interactions in activity participation and the derived demand for travel, paper presented at the EIRASS Conference on Activity-Based Approaches: Activity Scheduling and the Analysis of Activity Patterns.

HAGUE CONSULTING GROUP (1992), The Netherlands National Model, 1990: The National Model System for Traffic and Transport, Ministry of Transport and Public Works, The Netherlands.

KITAMURA R. (1996), Activity-Based Travel Demand Forecasting and Policy Analysis, paper presented at the TMIP Conference on Activity-Based Travel Forecasting, June 2-5, New Orleans, LA.

KRIZEK K. J. (2003), Neighborhood services, trip purpose, and tour-based travel, Transportation 30 (4), 387-410.

LEE Y., HICKMAN M., WASHINGTON S. (2007), Household type and structure, timeuse pattern, and trip-chaining behavior, Transportation Research Part A: Policy and Practice 41 (10), 1004-1020.

LEINBACH T. R. (2004), City Interactions: The Dynamics of Passenger and Freight Flows, In: Hanson S., Giuliano G. (Eds.), The Geography of Urban Transportation, The Guilford Press, New York and London.

MCNALLY M. G. (2007), The Activity-Based Approach, In: Hensher D. A., Button K. J. (Eds.), Handbook of transport modeling, Pergamon, $2^{\text {nd }}$ Edition.

MILLER E. J., ROORDA M. J., CARRASCO J. A. (2005), A Tour-Based Model of Travel Mode Choice, Transportation 32 (4), 399-422. 
MISRA R., BHAT C. R., SRINIVASAN S. (2003), Continuous time representation and modeling framework for the analysis of nonworker activity-travel patterns: tour and episode attributes, Transportation Research Record 1813, 11-20.

MILTHORPE F., DALY A. (2010), Comparison of Trip and Tour Analysis of Sydney Household Travel Survey Data, presented at Australasian Transport Research Forum, 29 September - 1 October 2010, Canberra, Australia Publication website: http://www.patrec.org/ atrf.aspx.

PAS E. I. (1997), Recent Advances in Activity-Based Travel Demand Modeling, Trave Model Improvement Program Report, Accessed on July 31, 2011 from: http://tmip.fhwa.dot.gov/ resources/clearinghouse/browse/list/16/233.

RECKER W. W. (1995), The household activity pattern problem: General formulation and solution, Transportation Research B: Methodological 29 (1), 61-77.

REICHMAN S. (1976), Travel adjustments and life styles: a behavioral approach, In: Stopher P. R., Meyburg A. H. (Eds.), Behavioral Travel-Demand Models, Lexington Books, Lexington, MA.

SHIFTAN Y. (1998), Practical approach to model trip chaining, Transportation Research Record 1645, 17-23.

SKM (2009), Critical Review of Transport Modelling Tools, National Transport Modelling Work Group, March, Available at: www.bitre.gov.au/info.aspx?Resourceld=734\&Nodeld=132.

TRANSPORTATION RESEARCH BOARD (TRB) (2007), Metropolitan Travel Forecasting, Current Practice and Future Directions (Special Report 288), Transportation Research Board, Washington, DC.

UNITED STATES DEPARTMENT OF TRANSPORTATION (USDOT) (1997), Activitybased Travel Forecasting Conference Proceedings, US Department of Transportation, Report DOT-T-97-17, Washington, DC.

VHB (2006), Results of FY2006 Travel Forecasting Research, Task 5: Review of Current Use of Activity-Based Modeling, Metropolitan Washington Council of Governments, National Capital Region Transportation Planning Board, Washington, DC.

VIRGINIA DEPARTMENT OF TRANSPORTATION (VDOT) (2009), Implementing Activity-Based Models in Virginia, VTM Research Paper 09-01.

WALLACE B., BARNES J., RUTHERFORD G. S. (2000), Evaluating the effects of traveler and trip characteristics on trip chaining, with implications for transportation demand management strategies, Transportation Research Record 1718, 97-106.

Initial submission: 12.09.2013

Revised submission: 28.04.2014

Final acceptance: 10.06.2014

Correspondence: Virginia Commonwealth University, 821 West Franklin Street, Richmond, VA 23284, United States

E-mail: xchen2@vcu.edu 
